\title{
Review Paper on RF based Energy Harvesting System
}

\author{
Parth Thakar \\ UG Student \\ Dwarkadas J. Sanghvi College of Engineering \\ Mumbai, India
}

\begin{abstract}
As the law of conservation of Energy states that energy can neither be created nor be destroyed, it can only be converted or transformed from one form to another, moreover there are various sources of energy like solar, wind, geothermal etc. The purpose of this paper is to put light on radio frequency based energy harvesting systems. The said RF energy is currently transmitted from various sources/transmitters which include mobile base stations, mobile, telephone, TV/radio broadcast stations and handheld radios. The propensity to gather or harvest RF energy from the committed sources empowers or authorizes wireless charging for low power appliances or devices which furthermore results in better product design dependableness and utilization. The battery operating systems can be charged gradually and slowly to abolish battery replacements or to extend battery durability disposable batteries can be used. The battery free systems i.e. RF energy based devices can be designed to work upon availability i.e. when the sufficient charge is accumulated. In all the cases mentioned above the devices or the appliances can be operated without the usage of cables battery panels connectors which can make these devices more mobile and portable while operation and charging as well. All this and more can be achieved by RF based energy harvesting and main cause or reason to harvest RF based energy is that it is consequentially FREE energy. The sources of RF energy are increasing day by day like mobile based transmitters from which more and more energy can be harvested. This paper more importantly focuses on parameters to design the system, methods, different frequency ranges that can be utilized and the respective circuitry for converting Low voltage output to High voltage for various applications using RF based energy harvesting.
\end{abstract}

\section{Keywords}

Energy, Radio Frequency, transmitter, Mobile Base Station, wireless charging, batteries, low and high voltage systems.

\section{INTRODUCTION}

Continuing the trend this paper primarily focuses on the radio frequency harvesting its applications numerous methods circuits and circuit losses which are explained further in this paper. As mentioned earlier that there are various sources of energy like energy due to vibrations, photovoltaic thermal and $\mathrm{RF}$ as well which can be harvested through different means.

\author{
Ameya Kadam \\ Assistant Professor \\ Dwarkadas J. Sanghvi College of Engineering \\ Mumbai, India
}

Table 1: Different Energy Sources and their Power Densities

\begin{tabular}{|c|c|}
\hline ENERGY SOURCES & $\begin{array}{l}\text { POWER } \\
\left(/ \mathrm{cm}^{2}\right)\end{array}$ \\
\hline RF & 0.01 to $0.1 \mu \mathrm{W}$ \\
\hline VIBRATION & 4 to $100 \mu \mathrm{W}$ \\
\hline PHOTOVOLTAIC & $10 \mu \mathrm{W}$ to $10 \mathrm{~mW}$ \\
\hline THERMAL & $20 \mu \mathrm{W}$ to $10 \mathrm{~mW}$ \\
\hline
\end{tabular}

These types of energy can be utilized further for different applications but the RF energy is more prominent mainly due to the reasons like it is free energy which is transmitted from the sources like mobile base stations, handheld radio, TV and other sources as well which can be harvested and used for operations like wireless charging of electrical devices like GPS and RLTS tracking transponders or tags or various medical sensors which are wearable as well, it can be used in building automation and various other applications in defense as well. In this paper we also shed a light on how to harvest this highly beneficial energy that is the methods of harvesting it through different circuit and technologies like RFID systems and also the advantages of using one over other. This paper gives a better perspective about different energy harvesting circuit topologies and types of harvesters that can be more coherent towards the society on the ground of costing more energy and time saving. Hence the RF energy harvesting is an optimistic technology which also acts a different source or an alternative source for the sensor nodes which can be charged wireless from the harvested RF energy. The different sources and their density of power drawn are mentioned in the table below.

Table 2: Power Density on Rfeh with Different Sources

\begin{tabular}{|c|c|c|}
\hline SOURCE & DISTANCE & $\begin{array}{c}\text { DENSITY } \\
\text { POWER } \\
\text { AVAILABLE }\end{array}$ \\
\hline $50 \mathrm{~kW} \mathrm{AM}$ & $5 / 10[\mathrm{~km}]$ & $159 / 40\left[\mu \mathrm{W} / \mathrm{m}^{2}\right]$ \\
RADIO & & \\
STATION & & $800 / 32 / 8\left[\mu \mathrm{W} / \mathrm{m}^{2}\right]$ \\
\hline $100 \mathrm{~W}$ GSM & $100 / 500 / 1000[\mathrm{~m}]$ & \\
BASE & & $40 / 1.6 / 0.4$ \\
STATION & & {$\left[\mathrm{mW} / \mathrm{m}^{2}\right]$} \\
\hline MOBILE & $1 / 5 / 10[\mathrm{~m}]$ & $80 / 3.2 / 0.84$ \\
PHONE & & {$\left[\mathrm{mW} / \mathrm{m}^{2}\right]$} \\
\hline 1W WI FI & $1 / 5 / 10[\mathrm{~m}]$ & \\
ROUTER & &
\end{tabular}




\section{SYSTEM OVERVIEW}

\subsection{Energy Harvesting Circuit RF
WAVES}

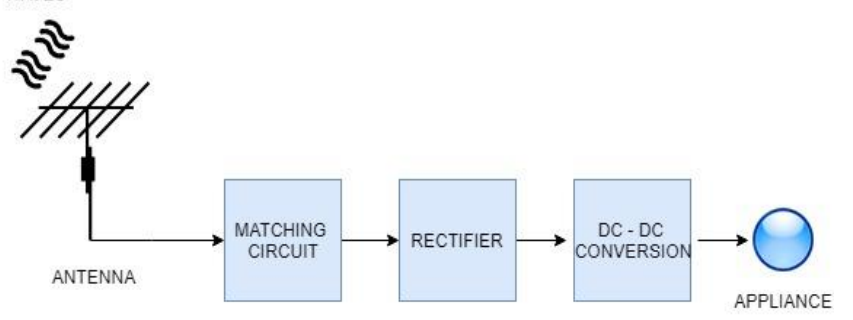

Figure 1

There are various sources of energy which can be converted and harvested like solar, water, coal geothermal etc. In this paper, it is mainly discussed bout RF energy that is radio frequency energy. This is transmitted mostly from the incident sources like mobile base stations telephones handheld radios and TV/radio broadcast stations. There are various applications and benefits of using and harvesting the said RF energy as it allows and empowers wireless charging for low power devices. This can result into devices without cables and wires and the main to harvest the radio frequency energy is that it is actually free energy which is generated from the above said sources and keeps on increasing as we are aware that there is a subsequent amount of increase in the sources mainly like the mobile base stations. The process of energy harvesting includes collection of the incident energy through antennas and it goes through the matching circuits after which it is converted into dc from $\mathrm{dc}$ to dc converters and is harvested as illustrated in the diagram.

\subsubsection{Matching Circuit}

The term matching circuit also known as impedance matching is or can be justified as a process of matching one impedance or making one impedance look like another. This is important or necessary to match a load to its source impedance of a driving source. There are a wide variety of parts and components and circuits used for the matching circuit. There are various applications or uses of the matching circuit or impedance matching which can be listed as follows:

- Receiving of signal from the power signal in an amplifier.

- Transfer of power from one stage to another in a transmitter.

\subsubsection{Rectifier}

An electric appliance or device which is composed or consist of one or more diodes that is used to metamorphose Alternate current $[\mathrm{AC}]$ to Direct current $[\mathrm{DC}]$. A diode can be defined as a one way valve which authorizes or allows the current to flow in one direction and this process is known as rectification. There are a numerous different physical forms a rectifier can take for e.g.: solid state diodes, vacuum tube diode, mercury arc valves and silicon based or controlled rectifiers and has various other silicon based semiconductor switches. There are various applications of rectifiers which can be listed as:

- Radio signals or detectors.

- De power supplies.
- A source of power instead of generating circuit etc.

As mentioned the rectifier is a device which is used to convert $\mathrm{AC}$ into DC, this is done because of the reason that AC flows or regularly reverses direction whereas the DC current flow into only one direction. After the process of rectification, the DC current that is produced is a type of DC that circumscribes or encloses active voltages and currents which are than altered into a type of voltage which further varies according to the currents end use.

\subsubsection{DC-2-DC Converter}

The dc $2 \mathrm{dc}$ converter is further discussed into the energy harvesting topologies section

\subsection{Energy Harvesting Circuit Losses}

When more energy saving or efficient energy harvester are wished for there are various factors or loss mechanisms which hinder this process or make it more tough to achieve high or better efficiencies more found in appliances or devices like diode connected transistors and diodes. In this section there are various such factors or ENERGY HARVESTING SERVICE LOSSES which can be listed as:

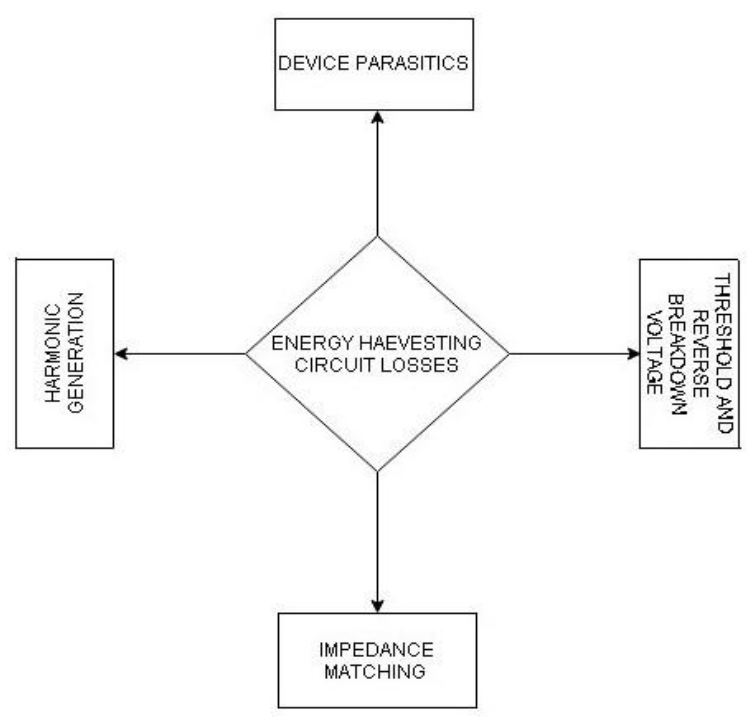

Figure 2. Energy Harvesting Circuit Losses

\subsubsection{Impedance Matching}

When and energy harvesting circuit is not properly complemented with its antenna, a part of its incident energy is reflected back to the environment from the antenna and is not properly absorbed or consumed due to which the energy available for rectifying is automatically deducted resulting into a loss of energy harvesting, Matching is usually more difficult in energy harvesting circuits as the impedance becomes different as a function of input power and frequency both because of the non-linearity of the rectifying elements.

\subsubsection{Harmonic Generation}

When we render a way to transfer a way this RF energy to dc the non-linearity of the diode is also a factor which results into a loss of this wireless energy. While the diode is being used it gives out frequency harmonics which result into the loss of the main power the incident power which as a result reduces a measure of this RF energy which is to be converted 
into dc resulting into less coherent harvesting of energy. As a result if the amount of incident power increases i.e. as the incident voltage keeps on increasing the loss of due energy due to harmonics keeps on increasing.

\subsubsection{Threshold and Reverse Breakdown Voltage}

Particularly the most principle or important reason for the coherency of the diode is the threshold or the turn on voltage. This parameter restricts the efficiency of the diode at low powers. Unless there is adequate amount of power incident on the RF energy harvester there won't be sufficient amount of energy to overcome this barrier or obstacle and charge the outgoing or the output capacitor. The reverse breakdown voltage of the diode also restricts the efficiency of the diode as this will only authorize the energy to short the diode. This scenario will only take place when the power levels are subsequently high and the dc bias is equivalent to half the breakdown voltage.

\subsubsection{Device Parasitic}

Device parasitic are also a reason or factor that causes an adequate amount of loss of RF energy harvesting. The resistance of the diode junction i.e. the junction diode resistance can also restrict the efficiency of the diode as the current moving of flowing in the diode will give or dissipate power in the semiconductor junction. Also due to reasons and causes like cutoff issues and high frequencies the junction capacitance can lead to significant minimal of performance. Mainly the diode work or operate under the maximum frequency which is limited by the junction capacitance. And there are reasons apart from this which are not mentioned as there numerous of those. Additionally the loss of the RF energy harvested also depends upon the lengths of the line that are chosen.

\subsection{R.F.I.D [Radio Frequency Identification]}

The new technology that has mastered a rapid growth recently is RIFD. A mainly simple RFID system consists of a reader and various numbers of tags [transponders]. This system has various application such as:

- Access control.

- Public transportation.

- Logistics.

- $\quad$ Airline baggage tracking etc.

Mainly there are 2 kinds of RFID tags operational currently which passive RFID tags and the other is active RFID tags. The passive ones operate under low frequencies and shorter range and on the other hand for applications of longer distances and frequencies the active RFID tags are operational. As the radio frequency energy is used for the lower power consumption technologies, there can be made a self-operated or self-powered which can be achieved via the usage of the radio frequency energy harvested. The principal source of the RF energy radiated for the passive transponders can be a central base station which is RF oriented. A common or most typical RF energy harvester works when the RF energy is rectified and stored to provide a dc supply.
Table 1: Rf Energy Conversion Efficiencies In 2.45 Ghz

\begin{tabular}{|c|c|c|c|c|}
\hline $\begin{array}{c}\text { EFFICIEN } \\
\text { CY } \\
{[\%]}\end{array}$ & $\begin{array}{c}\text { INPUT } \\
\text { POWER } \\
{[\mathrm{dBm}]}\end{array}$ & $\begin{array}{c}\text { FREQU } \\
\text { ENCY } \\
{[\mathrm{MHz}]}\end{array}$ & $\begin{array}{c}\text { RECTIFIE } \\
\text { R } \\
\text { ELEMENT }\end{array}$ & SOURCE \\
\hline 15 & -20 & 2450 & $\begin{array}{c}\text { Avago } \\
\text { HSMS- }\end{array}$ & {$[36]$} \\
& & & 2852 Si & \\
& & & Schottky & \\
\hline 28 & -20 & 2450 & Avago & {$[37]$} \\
& & & HSMS- & \\
& & & 2852 Si & \\
& & & Schottky & \\
\hline 45 & -10 & 2450 & Avago & {$[36]$} \\
& & & HSMS- & \\
& & & 2852 Si & \\
& & & Schottky & \\
\hline 57 & 0 & 2450 & Avago & {$[35]$} \\
& & & HSMS- & \\
& & & 282x Si & \\
& & & Schottky & \\
\hline
\end{tabular}

\subsubsection{UHF Energy Harvesters}

Table 2: Uhf Conversion Efficiencies

\begin{tabular}{|c|c|c|c|c|}
\hline $\begin{array}{c}\text { EFFICIEN } \\
\text { CY } \\
{[\%]}\end{array}$ & $\begin{array}{c}\text { INPUT } \\
\text { POWER } \\
{[\mathrm{dBm}]}\end{array}$ & $\begin{array}{c}\text { FREQ } \\
\text { UENC } \\
\mathrm{Y} \\
{[\mathrm{MHz}]}\end{array}$ & $\begin{array}{c}\text { RECTIFIE } \\
\mathrm{R} \\
\text { ELEMENT }\end{array}$ & SOURCE \\
\hline 1.2 & -14 & 950 & $\begin{array}{c}0.3-\mathrm{nm} \\
\text { CMOS } \\
\text { transistor }\end{array}$ & {$[36]$} \\
\hline 5.1 & -14.1 & 920 & $\begin{array}{c}\text { 0.18-nm } \\
\text { CMOS } \\
\text { transistor }\end{array}$ & {$[37]$} \\
\hline 11 & -14 & 915 & $\begin{array}{c}90-\mathrm{nm} \\
\text { CMOS } \\
\text { transistor }\end{array}$ & {$[36]$} \\
\hline 12.8 & -19.5 & 900 & $\begin{array}{c}\text { 0.18-nm } \\
\text { CMOS, } \\
\text { CoSi2-Si } \\
\text { Schottky }\end{array}$ & \\
\hline & & & & \\
\hline
\end{tabular}

The Ultra High Frequency harvesters are mainly made or designed for very minimal and low power consumption that is below $0 \mathrm{dBm}$. This type of design is actually made by the RFID technology users which work in the 865-928 MHz regions. As mentioned earlier that the passive RFID tags operate for short ranges and low frequencies therefore they must lookout or hunt for energy which is available far from their readers in the multipath environments. Accordingly the values or the reported energy levels and the efficiencies of the energy harvester in the table are with respect to the power level cutoffs are mainly around $-20 \mathrm{dBm}$. Mainly to shelter 
high voltage levels for the utilization of the digital peripherals or the electronics at these minimal power levels the UHF harvesters have used various multiplatform rectifiers like the modified clock ford Walton and the Dickson charge pump.

\subsubsection{Microwave Energy Harvesters}

Table 3: Microwave Conversion Efficiencies At $5.8 \mathrm{Ghz}$

\begin{tabular}{|c|c|c|c|c|}
\hline $\begin{array}{c}\text { EFFICI } \\
\text { ENCY } \\
{[\%]}\end{array}$ & $\begin{array}{c}\text { INPUT } \\
\text { POWER } \\
{[\mathrm{dBm}]}\end{array}$ & $\begin{array}{c}\text { FREQU } \\
\text { ENCY } \\
{[\mathrm{MHz}]}\end{array}$ & $\begin{array}{l}\text { RECTIFIER } \\
\text { ELEMENT }\end{array}$ & SOURCE \\
\hline 23 & -10 & 5800 & $\begin{array}{c}\text { Unspecified } \\
\text { Schottky }\end{array}$ & {$[32]$} \\
\hline 51.5 & 10 & 5800 & $\begin{array}{c}\text { Avago } \\
\text { HSMS-8202 } \\
\text { Si Schottky }\end{array}$ & [33] \\
\hline 54 & 0 & 5800 & $\begin{array}{c}\text { Unspecified } \\
\text { Schottky }\end{array}$ & [32] \\
\hline 59.3 & 18 & 5800 & $\begin{array}{c}\text { M/A-COM } \\
\text { 4E2054 } \\
\text { GaAs } \\
\text { Schottky }\end{array}$ & [34] \\
\hline
\end{tabular}

There are various number of advantages of using the microwave energy harvester in comparison to the RFID applications which are the following: the microwave antennas are much smaller as compared to the UHF antennas and this further becomes more helpful as these smaller antennas help to minimize the antenna aperture and more easily focuses the antenna beams.

As the size of the antenna is a major and more principal component as compared to the size of the RFID enabled sensors or the rectennas, the left over space and the weight reduced as well can be used or the can help in the reduction for ground based systems for power collections.

The operation of the microwave energy efficiencies at the 5.8 $\mathrm{GHz}$ for the RFID has been very much beneficial due to the reasons mentioned below like:

- Techniques for more spatial signaling.

- Ability of plasma penetration.

- Minimal effects of degradation caused due to the antennas operations on various materials or objects.

- More efficient material sensing ability.

And various others.
Table 4: Microwave Conversion Efficiencies Above 5.8 Ghz

\begin{tabular}{|c|c|c|c|c|}
\hline $\begin{array}{c}\text { EFFICI } \\
\text { ENCY } \\
{[\%]}\end{array}$ & $\begin{array}{c}\text { INPUT } \\
\text { POWER } \\
{[\mathrm{dBm}]}\end{array}$ & $\begin{array}{c}\text { FREQU } \\
\text { ENCY } \\
\\
{[\mathrm{MHz}]}\end{array}$ & $\begin{array}{l}\text { RECTIFIER } \\
\text { ELEMENT }\end{array}$ & SOURCE \\
\hline 60 & 21.5 & 10000 & $\begin{array}{c}\text { Alpha } \\
\text { Industries } \\
\text { DMK6606 } \\
\text { GaAs } \\
\text { Schottky }\end{array}$ & [42] \\
\hline 4.5 & -2 & 25700 & $\begin{array}{c}\text { M/A-COM } \\
\text { 4E2502L Si } \\
\text { Schottky }\end{array}$ & [43] \\
\hline 15.5 & 8 & 25700 & $\begin{array}{c}\text { M/A-COM } \\
\text { 4E2502L Si } \\
\text { Schottky }\end{array}$ & [43] \\
\hline 35 & 10.6 & 35000 & $\begin{array}{c}\text { M/A-COM } \\
\text { 4E1317 } \\
\text { GaAs } \\
\text { Schottky }\end{array}$ & [44] \\
\hline
\end{tabular}

\subsection{Energy Harvesting Topologies}

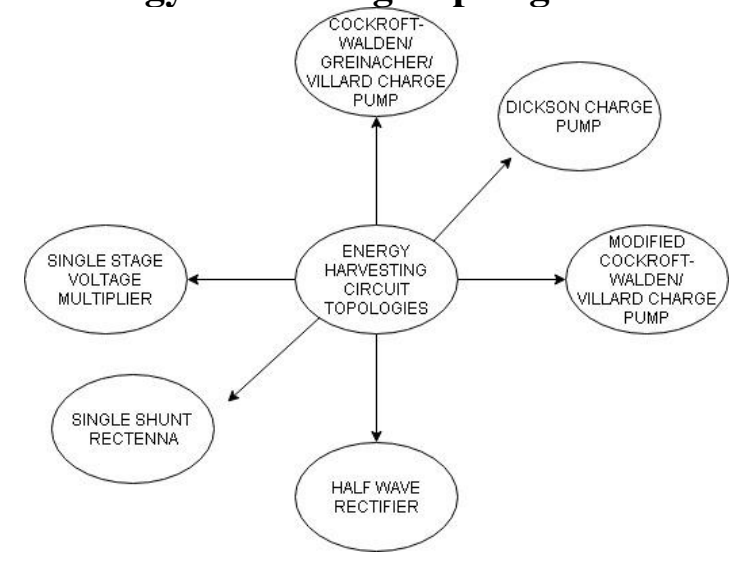

Figure 3. Energy Harvesting Topologies

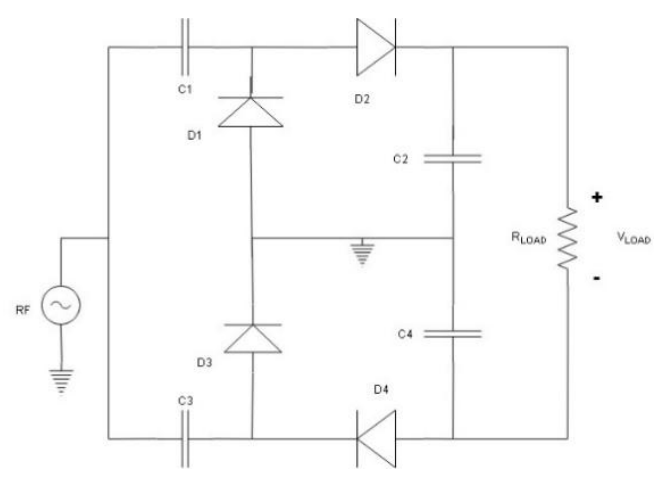

Figure 4: Modified Cockcroft-Walton/Greinacher charge pump 

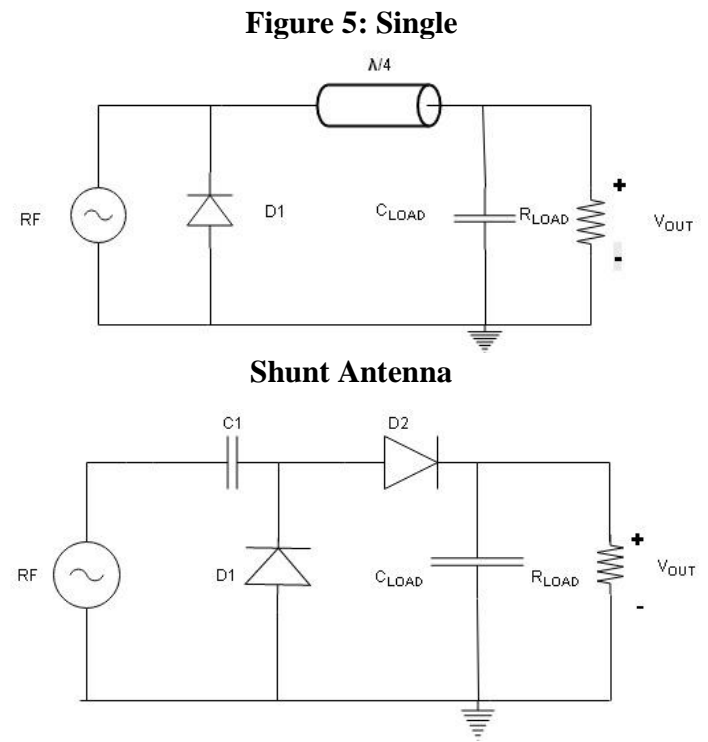

Figure 6: Single stage voltage multiplier

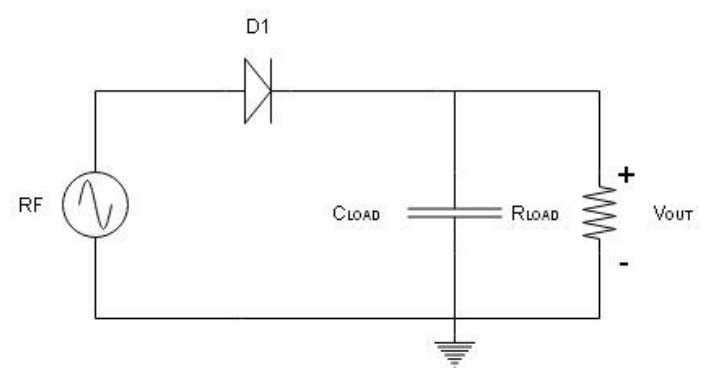

Figure 7: Half Wave Rectifier

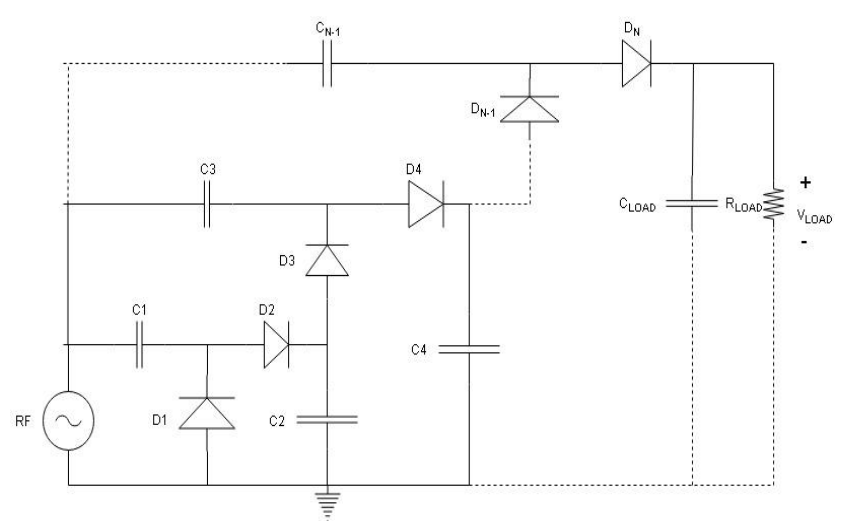

Figure 8: Dickson charge pump

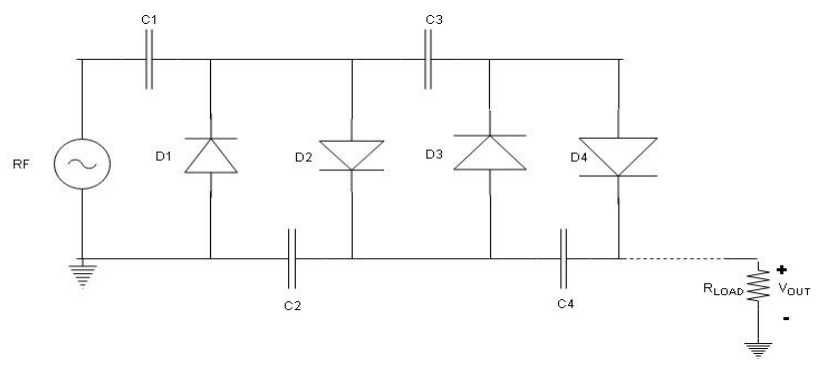

Figure 9: Cockcroft-Walton/Greinacher/Villard charge pump
The above shown topologies are used to convert the available Radio frequency Energy into dc. There are multiple ways to do it but the most commonly used are diode based rectifier circuits. The above shown figure manifests few types. Rectennas have very high efficiency and available power densities are very huge, it is usually used by SPS community. Schottkey diodes have large power handling capacity and are unnecessary to use in this type of application. Nevertheless, RF can harvest immense amount of energy but the dc output produced is very low which is not sufficient to run any electrical appliances so charge pumps are used. They not only rectify the voltage but also steps up the output by utilizing various cascaded capacitor-diode stages. The Dickinson pump charge doesn't require any conversion of $\mathrm{AC}$ or any transformers, it utilizes diodes or various different switching elements to move charge between capacitors in stages, individually, every voltage will increase the supply voltage. Cockcroft Walton is made by utilizing ladder network of voltage multiplier using capacitors and diodes. In the modified version at front end there is a half bridge and rectifier at the end of the back. These parameters lead to balance the voltages.

\section{CONCLUSION}

We studied different circuit topologies which can be further applied for the application purposes i.e. stepping up the output voltage according to the requirement. The system was studied in detail with different losses related to the circuit. There are different frequencies available for utilizing the RF energy which are being provided in the introduction as well as the RFID part of the respective paper. Our further research would be using different types of antenna such as patch antenna, micro strip antenna, horn antenna and developing actual application based circuit and concluding by comparative study of the output obtained by all of them.

\section{REFERENCES}

[1] Lu, Xiao, et al. "Wireless Networks with RF Energy Harvesting: A Contemporary Survey." IEEE Communications Surveys \& Tutorials, vol. 17, no. 2, 2015, pp. 757-789., doi:10.1109/comst.2014.2368999.

[2] Griguer, Hafid, et al. "Design Rules for RF Micro Energy Harvesting under near Field Probing Considerations." 2015 27th International Conference on Microelectronics (ICM),

2015 , doi:10.1109/icm.2015.7438043.

[3] Nalini, M., et al. "Energy Harvesting and Management from Ambient RF Radiation." 2017 International Conference on Innovations in Green Energy and Healthcare Technologies (IGEHT), 2017, doi:10.1109/igeht.2017.8094073.

[4] Kim, Sangkil, et al. "Ambient RF Energy-Harvesting Technologies for Self-Sustainable Standalone Wireless Sensor Platforms." Proceedings of the IEEE, vol. 102, no. 11, 2014, pp. 1649-1666, doi:10.1109/jproc.2014.2357031.

[5] Mnif, Mohamed Mokhles, et al. "New Design of RF-DC Rectifier Circuit for Radio Frequency Energy Harvesting." 2016 IEEE International Conference on Electronics, Circuits and Systems (ICECS), 2016, doi:10.1109/icecs.2016.7841289.

[6] Chowkwale, Bhakti, et al. "Energy Harvesting Techniques for Low Power RF Sensors." 2015 17th 
International Conference on Advanced Communication Technology (ICACT), 2015, doi:10.1109/icact.2015.7224755.

[7] Kurvey, Mamta, and Ashwini Kunte. "Design and Optimization of Stepped Rectangular Antenna for RF Energy Harvesting." 2018 International Conference on Communication Information and Computing Technology (ICCICT), 2018, doi:10.1109/iccict.2018.8325885.

[8] [Aboueidah, Hadeel, et al. "Characterization of RF Energy Harvesting at 2.4 GHz." 2017 24th IEEE International Conference on Electronics, Circuits and Systems (ICECS), 2017, doi:10.1109/icecs.2017.8292118.

[9] Khansalee, Ekkaphol, et al. "A Dual-Band Rectifier for RF Energy Harvesting Systems." 2014 11th International Conference on Electrical Engineering/Electronics, Computer, Telecommunications and Information Technology (ECTI-CON), 2014, doi:10.1109/ecticon.2014.6839870.

[10] Ababneh, Majdi M., et al. "Optimized Power Management Circuit for RF Energy Harvesting System." 2017 IEEE 18th Wireless and Microwave Technology Conference (WAMICON), 2017, doi:10.1109/wamicon.2017.7930238.

[11] Andrenko, Andrey S., et al. "Outdoor RF Spectral Survey: A Roadmap for Ambient RF Energy Harvesting." TENCON 2015 - 2015 IEEE Region 10 Conference, 2015, doi:10.1109/tencon.2015.7373140.

[12] Partal, Hakan P., et al. "Design and Implementation of a RF Energy Harvesting Module with DC Power Control." 2018 22nd International Microwave and Radar Conference (MIKON), 2018, doi:10.23919/mikon.2018.8405216.

[13] Ronghe, Sushil B., and Varada Potnis Kulkarni. "Modelling and Performance Analysis of RF Energy Harvesting Cognitive Radio Networks." 2016 International Conference on Communication and Electronics Systems (ICCES), 2016, doi:10.1109/cesys.2016.7889819.

[14] Merz, Christian, and Gerald Kupris. "High Q Impedance Matching for RF Energy Harvesting Applications." 2016 3rd International Symposium on Wireless Systems within the Conferences on Intelligent Data Acquisition and Advanced Computing Systems (IDAACS-SWS), 2016, doi:10.1109/idaacs-sws.2016.7805784.

[15] Kitazawa, Shoichi, et al. "Energy Harvesting from Ambient RF Sources." 2012 IEEE MTT-S International Microwave Workshop Series on Innovative Wireless Power Transmission: Technologies, Systems, and Applications, 2012, doi:10.1109/imws.2012.6215815.

[16] Noguchi, Akira, and Hiroyuki Arai. "Small Loop Rectenna for RF Energy Harvesting." 2013 Asia-Pacific Microwave Conference Proceedings (APMC), 2013, doi:10.1109/apmc.2013.6695199.

[17] Dai, Haojuan, et al. "A Review and Design of the onChip Rectifiers for RF Energy Harvesting." 2015 IEEE International Wireless Symposium (IWS 2015), 2015, doi:10.1109/ieee-iws.2015.7164642.
[18] Gamal, Hossam Mahmoud, et al. "Novel Radio Frequency Energy Harvesting Model." 2012 IEEE International Power Engineering and Optimization Conference, 2012, doi:10.1109/peoco.2012.6230862.

[19] Pirapaharan, K, et al. "Energy Harvesting through the Radio Frequency Wireless Power Transfer." 2013 IEEE International $R F$ and Microwave Conference (RFM), 2013, doi:10.1109/rfm.2013.6757288.

[20] Thakuria, Tapashi, and Tulshi Bezboruah. "Design of an Efficient RF Energy Harvesting System at 900 MHz." 2018 5th International Conference on Signal Processing and Integrated Networks (SPIN), 2018, doi:10.1109/spin.2018.8474258.

[21] Priya, Shashank, and D. J. Inman. Energy Harvesting Technologies. Springer, 2010.

[22] Karl, Holger, et al. Wireless Sensor Networks: First European Workshop, EWSN 2004, Berlin, Germany, and January 19-21, 2004: Proceedings. Springer-Verlag, 2004.

[23] Rashid, Muhammad H. Electric Renewable Energy Systems. Academic Press Is an Imprint of Elsevier, 2015.

[24] Tran, Le-Giang, et al. "RF Power Harvesting: a Review on Designing Methodologies and Applications." Micro and Nano Systems Letters, vol. 5, no. 1, 2017, doi:10.1186/s40486-017-0051-0.

[25] Seah, Winston K.g., et al. "Wireless Sensor Networks Powered by Ambient Energy Harvesting (WSN-HEAP) Survey and Challenges." 2009 1st International Conference on Wireless Communication, Vehicular Technology, Information Theory and Aerospace \& Electronics Systems Technology, 2009, doi:10.1109/wirelessvitae.2009.5172411.

[26] Che, W., et al. "Power Management Unit for Battery Assisted Passive RFID Tag." Electronics Letters, vol. 46, no. 8, 2010, p. 589, doi:10.1049/el.2010.0113.

[27] Valenta, Christopher R, and Gregory D Durgin. "Harvesting Wireless Power: Survey of EnergyHarvester Conversion Efficiency in Far-Field, Wireless Power Transfer Systems." IEEE Microwave Magazine, vol. 15, no. 4, 2014, pp. 108-120., doi:10.1109/mmm.2014.2309499.

[28] K. Nishida, Y. Taniguchi, K. Kawakami, Y. Homma, H. Mizutani, M. Miyazaki, H. Ikematsu, and N. Shinohara, "5.8 GHz high sensitivity rectenna array," in Proc. IMWS-IWPT, 2011, pp. 19-22.

[29] D. Wang and R. Negra, "Design of a dual-band rectifier for wireless power transmission," in Proc. 2013 IEEE Wireless Power Transfer, May 2013, pp. 127-130.

[30] S. Imai, S. Tamaru, K. Fujimori, M. Sanagi, and S. Nogi, "Efficiency and harmonics generation in microwave to DC conversion circuits of half-wave and full-wave rectifier types," in Proc. IMWSIWPT, 2011, pp. 15-18.

[31] S. Mbombolo and C. Park, "An improved detector topology for a rectenna," in Proc. IMWS-IWPT, 2011, pp. 23-26.

[32] U. Olgun, C. Chen, and J. Volakis, "Wireless power harvesting with planar rectennas for $2.45 \mathrm{GHz}$ RFIDs," 
in Proc. 2010 URSI Int. Symp. Electromagnetic Theory, 2010, pp. 329-331.

[33] U. Olgun, C. Chen, and J. Volakis, "Investigation of rectenna array configurations for enhanced RF power harvesting," IEEE Antennas Wireless Propag. Lett., vol. 10, pp. 262-265, Apr. 2011.

[34] T. Ume, H. Yoshida, S. Sikine, Y. Fujita, T. Suzuki, and S. Otaka, "A 950-MHz rectifier circuit for sensor network tags with 10-m distance," IEEE J. Solid-State Circuits, vol. 41, no. 1, pp. 35-41, Jan. 2006.

[35] A. Shameli, A. Safarian, A. Rofougaran, M. Rofougaran, and F. De Flaviis, "Power harvester design for passive UHF RFID tag using a voltage boosting technique," IEEE Trans. Microwave Theory Tech., vol. 55, no. 6, pp. 1089-1097, June 2007.

[36] G. Papotto, F. Carrara, and G. Palmisano, "A 90-nm CMOS threshold-compensated RF energy harvester," IEEE Trans. Solid-State Electron., vol. 46, no. 9, pp. 1985-1997, Sept. 2011.

[37] J. Lee, B. Lee, and H. Kang, "A high sensitivity CoSi2Si Schottky diode voltage multiplier for UHF-band passive RFID tag chips," IEEE Microwave Wireless Compon. Lett., vol. 18, no. 12, pp. 830-832, Dec. 2008.
[38] T. Yoo and K. Chang, "Theoretical and experimental development of 10 and $35 \mathrm{GHz}$ rectennas," IEEE Trans. Microwave Theory Tech., vol. 40, no. 6, p. 8, June 1992.

[39] A. Collado and A. Georgiadis, " $24 \mathrm{GHz}$ substrate integrated waveguide (SIW) rectenna for energy harvesting and wireless power transmission," in Proc. 2013 IEEE Int. MTT-S, pp. 1-3.

[40] Y. Ren, M. Li, and K. Chang, "35 GHz rectifying antenna for wireless power transmission," Electron. Lett., vol. 43, no. 11, pp. 602-603, Nov. 2007.

[41] Shinohara, Naoki. "Rectennas for Microwave Power Transmission." IEICE Electronics Express, vol. 10, no. 21, 2013, pp. 20132009-20132009. doi:10.1587/elex.10.20132009.

[42] Williams, Al. "Circuit VR: The Dickson Charge Pump." Hackaday, $6 \quad$ Apr. 2018 hackaday.com/2018/04/06/circuit-vr-the-dickson-chargepump/.

[43] Liu, Junfeng, et al. "Modified Voltage Equaliser Based on Cockcroft-Walton Voltage Multipliers for SeriesConnected Supercapacitors." IET Electrical Systems in Transportation, vol. 8, no. 1, 2018, pp. 44-51., doi:10.1049/iet-est.2017.0016 